\title{
The problems of massive small bowel resection and difficulties encountered in management
}

\author{
A. A. B. BARros D'SA \\ M.D., F.R.C.S., F.R.C.S.Ed
}

\author{
T. G. PARKS \\ M.Ch., F.R.C.S.
}

\author{
A. D. RoY \\ F.R.C.S. \\ Department of Surgery, The Queen's University of Belfast
}

\begin{abstract}
Summary
Massive small bowel resection is imperative in the management of several pathological conditions and is accompanied by high operative mortality. In those that survive, serious nutritional disturbances are inevitable. Intestinal adaptation is said to occur but cannot be relied upon. Long-term parenteral nutrition is problematical and often unsuccessful. Many surgical procedures have been adopted in an effort to improve prognosis and have been found wanting. Controlled experimental studies in the use of reversed segments and a limited number of reported clinical cases using the method after massive resection suggest that this technique may improve the function of the residual intestine to such an extent that other supportive measures are unnecessary.
\end{abstract}

\section{Introduction}

In 1881, Koeberle reported the first case of bowel resection and for a long time the term 'massive' was used to designate resections of $200 \mathrm{~cm}$ or more of small bowel. Haymond (1935) reviewed a collected series of 257 cases and came to the conclusion that excision of up to one-third of the small bowel was a safe procedure and that good absorption was likely to follow. Chen (1969) studied twelve patients and found that absorption and nutrition were seriously impaired by resections of $50-75 \%$ of small bowel. Experimental studies have shown that dogs will tolerate a maximum resection of two-thirds of small bowel with better survival figures after proximal rather than distal resections (Kunz and Molitor, 1928; Kremen, Linner and Nelson, 1954). The convention originally adopted that massive resection was equivalent to the loss of $200 \mathrm{~cm}$ or more of small bowel is no longer valid. The definition of massive resection and of the minimum residual length compatible with survival has to be arbitrary as many factors influence the outcome.

Requests for reprints to Mr A. A. B. Barros D'Sa, F.R.C.S.. Department of Surgery, The Queen's University of Belfast, Institute of Clinical Science, Grosvenor Road, Belfast BT12 6BJ.
The three commonest diseases requiring resection are infarction of the bowel due to vascular or mechanical causes, extensive involvement by Crohn's disease and trauma to the bowel and its blood supply (Colcock and Braasch, 1968). Of these, Sautier et al. (1970) found Crohn's disease to be the most frequent cause, while Alexandre (1970) stated that vascular diseases, chiefly mesenteric thromboembolism, represented the most frequent and most severe causative factors. More recently, vascular occlusion, occurring especially in the form of mesenteric vein thrombosis in otherwise healthy young women, has been attributed to oral contraceptives (Reed and Coon, 1963.

Mortality is high and varies in different series from 66 to $80 \%$. Alexandre (1970) noted an immediate mortality rate of up to $70 \%$. All surviving and fatal cases must be included to obtain accurate estimates of mortality following massive resection. Despite numerous reports in the literature, this is not possible because of the tendency not to report unsuccessful cases.

\section{Pathophysiology}

In the past, an inordinate amount of attention was given to the actual length of bowel resected. This is of much less importance than the function of the residual bowel, which will dictate survival and its quality. Although short-term survival has been reported with extremely short remnants of intestine (Kinney et al., 1962), cases of long-term survival are very uncommon (Meyer, 1968). It is impossible, however, to define precisely the minimum length of healthy small bowel on which a normal life or survival depends. Surveys of collected cases of extensive resection indicate that normal absorptive patterns and weight can be maintained only if $50 \%$ of healthy small bowel remains (Haymond, 1935). With very small remnants, life is abnormal and survival becomes the main concern.

The prognosis is also governed by other factors. The pathology for which many patients have resections is associated with advancing age (Haymond, 
1935). The intrinsic nature of the lesion necessitating resection is of relevance, for example, those with superior mesenteric vascular occlusion may infarct the entire small bowel and proximal colon, and after resections for Crohn's disease, the residual bowel may retain a potential for recurrence. Further, there is evidence to show that distal resections are certainly less well tolerated than proximal ones (Kremen et al., 1954), the ileum having a greater capacity for structural and functional adaptation (Weser and Hernandez, 1971). When proximal resection is massive, the adequacy of the remaining rate-limited active transport systems in the distal remnant will depend on the solute concentration of its contents. This may result in osmotic diarrhoea (Kerpel-Fronius, Miltenyi and Gorgenyi, 1970). The role of the ileo-caecal valve in preventing malnutrition after massive resection has been emphasized in both experimental and clinical studies (Kremen et al., 1954; Kogan et al., 1957; Chen, 1969). Diarrhoea is a major symptom after massive resection and the importance of the colon as a reservoir and absorptive site for water and electrolytes is obvious.

Advances have been made in the study of intestinal adaptation in the remnant following massive resection in both animals and man (Grenier et al., 1973). Factors considered to be responsible for triggering this change seem to be intralumenal nutrition (Dowling, 1974) and probably hormonal agents (Loran and Carbone, 1968) among a host of other possibilities. Structural adaptation in terms of height of villi and mucosal cell mass in the remnant have been observed in animals (Weser and Hernandez, 1971) and man (Weinstein et al., 1969). It is still not known whether the observed villous hyperplasia is due to accelerated cell proliferation or to the rate of cell migration. In man, the histomorphological changes observed were found to correlate well with absorption (Fletcher et al., 1960) but these findings were by no means universally confirmed (Kinney et al., 1962). Wilkinson (1973) stated that, in spite of claims to the contrary, the intestinal remnant in infants and children does not hypertrophy or dilate unless there is intestinal obstruction. In the current state of knowledge, the evidence that intestinal adaptation follows massive resection finds greater unanimity of support from experimental rather than clinical studies. The negative reports in the literature give reason for disquiet, particularly if the process is to be relied upon for survival. That the adaptive response can be positive and beneficial is undeniable, but the varying individual capacity for adaptation has to be taken into account.

In reviewing the literature on absorption studies after massive resection, it is discovered that steatorrhoea is one of the most significant and consistent defects. This is evident when one considers the disturbances in the several phases of the process of fat absorption excellently illustrated by Westergaard and Dietschy (1974). An examination of the various rate-limiting steps will demonstrate that massive resections produce defective lipolysis owing to poor lipase output and a low intralumenal pH (Kogan et al., 1957), as well as insufficient micellar solubilization owing to depletion of the bile salt pool (Lack and Weiner, 1967). The cumulative effect of these defects, loss of absorbing area and rapid transit of intralumenal contents will produce deficient mucosal uptake and re-esterification of fat with consequent steatorrhoea. This is accompanied by malsorption, principally of fat-soluble vitamins (Althausen et al., 1950), calcium and phosphorus (Kinney et al., 1962).

Absorption of proteins is likely to be impaired but not to as great an extent as that of fat. Carbohydrate absorption is least likely to be affected, but flattened glucose tolerance curves have been observed after massive resection (Althausen et al., 1950).

A deficit in total body water is usually encountered following the removal of the proximal colon and to a lesser extent the ileum. The remaining mucosal transport systems become overloaded and a solutetype diarrhoea with substantial fluid and electrolyte loss is produced (Kerpel-Fronius et al., 1970). Hypokalaemia and hypomagnesaemia can be severe (Fletcher et al., 1960; Chen, 1969), and there is often a tendency towards metabolic acidosis.

Most water-soluble vitamins are absorbed with ease, but deficiencies have been documented (Althausen et al., 1950). A frequent complication is anaemia, often of a mixed type, resulting from deficiencies of iron, folic acid and vitamin $\mathbf{B}_{12}$.

One of the main features of massive resection is an increase in the rate of transit of intralumenal contents, in particular, if the resection is distal (Sautier et al., 1970), or if the ileo-caecal valve is not preserved (Kremen et al., 1954). Experimental reports and clinical experience of this problem are similar. Sequelae such as gut hypermotility and gastric acid hypersecretion are recognized (Frederick, Sizer and Osborne, 1965; Wright and Tilson, 1973) but knowledge of the exact mechanisms by which they are produced remains fragmentary. Various theories have been advanced to explain the occurrence of gastric acid hypersecretion but these are not adequately substantiated (Buxton, 1974). There is some evidence to suggest that hormonal factors may be responsible for these complications (Osborne, Frederick and Blair, 1966; Barros D'Sa et al., 1975b; Barros D'Sa and Buchanan, 1977).

\section{Conservative management}

Although the consequences of resection differ in 
pattern and intensity, a syndrome of conditioned malnutrition invariably follows. Conservative treatment requires meticulous daily control over a long period based on a knowledge of the absorptive capacity of the remaining intestinal mucosa. If a prescribed dietary regime is not strictly adhered to, metabolic deficiencies may follow.

Comprehensive parenteral nutrition is recommended and is said to favour better and faster functional adaptation. To this end, various routes and methods of providing fluid and nutritional needs have been described. For a limited period the total daily requirements can be ensured, but long-term parenteral nutrition is fraught with difficulties and dangers (Sedgwick and Goodman, 1971) with additional problems arising from recumbency and protracted stay in hospital. Parenteral and oral dietary regimes including supplements designed to meet the specific requirements of a patient have to be based on careful tolerance studies. Crippling diarrhoea may be reduced by treatment with cholestyramine. Fat administered in the form of medium-chain triglycerides permits absorption independently of bile salts directly into the bloodstream rather than via the lacteals (Zurier et al., 1966). This treatment is not always successful. Caution in the use of elemental 'space-diets' is advised (Wright and Tilson, 1973).

The rare case reports in the literature of survival on very short lengths of remnant form a poor basis for formulating a conservative policy of treatment. Such a policy does not emphasize sufficiently the high mortality and severe morbidity which attend resection. The expectation that intestinal adaptation will take place with conservative treatment applies only to those who, in retrospect, have the capacity to adapt and survive. Patients succumb despite all the sophisticated measures undertaken to keep them alive (Dubost, 1972).

\section{Surgical measures in management}

The long-term unreliability of such measures has led to the trial of numerous adjunctive surgical procedures to improve nutritional status. Success with vagotomy and pyloroplasty in diminishing gastric acid hypersecretion was reported by Frederick et al. (1965), but the rationale and efficacy of this operation must be questioned. In a small experimental study, bilateral splanchnicectomies were done to improve absorption by augmenting intestinal blood flow (Mackby et al., 1965). In the main, surgical treatment has been directed towards preventing accelerated transit with the hope of enhancing the absorptive capacity of the remnant. A variety of recirculating loops (Mackby et al., 1965), artificial sphincters (Schiller, Di Rio and Anderson, 1967), valves (Waddell et al., 1970) and an assortment of pouches (Poth, 1969) have been tried and generally relegated owing to complications arising from the procedure itself. Vayre, Hureau and Soyer (1967) introduced colonic interposition in dogs as a method suitable to situations in which the small bowel remnant is short or absent. The variety and number of techniques devised underlines the desperation experienced in treatment.

The idea of reversal of small bowel segments, first conceived in the late nineteenth century, was revived and has been used in the treatment of selected cases of the dumping syndrome and post-vagotomy diarrhoea (Herrington et al., 1968). Early experimental data in the use of reversed segments for serious gut loss produced conflicting results as to its value (Mackby et al., 1965; Venables, Ellis and Smith, 1966).

The reversal of inappropriate lengths of bowel sited at unfavourable points along the remaining bowel produced problems and created apprehension in the use of this procedure. Until recently, the ideal site for reversal remained a controversial issue. There have been reports that reversal of a segment at the distal end rather than in the proximal part of the remnant gave better results in pigs (Kieninger, 1974) and this has been the experience in dogs (Barros D'Sa, 1975b). A reversed segment in the terminal part of the remnant (Fig. 1) allows maximal exploitation of the potential absorptive capacity of the remnant. By contrast a proximal segmental reversal may produce hyperacidity (Grundberg, Lopez and Dragstedt, 1967).

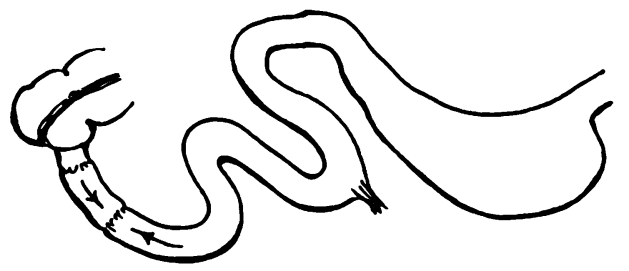

Fig. 1. Diagrammatic representation of segmental reversal in the terminal portion of the remnant.

The elegant technique of reversal suggested by Rygick and Nasarov (1969) was bound to be impracticable when using optimal lengths of bowel (Barros D'Sa, 1975b). A guarded approach to intestinal reversal has therefore been understandable. The ideal length of reversal was generally taken to be within the range 7.5-14 cm (Leading Article, 1975). Twenty-seven out of thirty-one reversed segments used clinically were within these limits (Barros D'Sa, $1975 \mathrm{a})$ and more than half of them were $7 \cdot 5-10 \mathrm{~cm}$ long with no resultant complications. A well planned 8 to $10 \mathrm{~cm}$ segment with an adequate vascular pedicle should be aimed at. The technique of axial 
rotation of the pedicle to the reversed segment seems eminently suitable (Fig. 2) and in this regard the advice of Ellis and Coll (1968) to observe the segment for a period after construction of the reversal is an adequate precaution. Another question that requires clarification is the ideal timing of the insertion of the reversed segment, i.e. whether it should be done at the initial operation or after an interval. Little experimental work has been done to answer these queries (Barros D'Sa, Kennedy and Parks, 1976a).

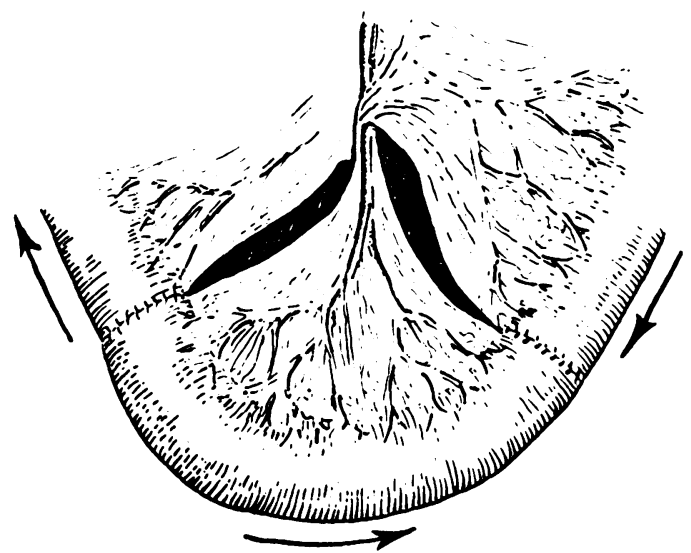

Fig. 2. Technique of construction of a reversed segment after axial rotation of the pedicle.

Grenier et al, (1973) reviewed the several surgical methods of treatment to combat the results of massive gut resection and suggested that reversed segments might be the most efficient way of doing so. More recent controlled experimental studies undertaken to assess the functional value of segmental reversal reinforces these views (Barros D'Sa et al., 1974; Barros D'Sa, 1975b).

Against a background of confused experimental information, Gibson, Carter and Hinshaw (1962) were the first to apply the procedure successfully in patients. Since then there have been a total of twentyseven cases reported in the literature most of which recorded highly favourable results, although others were inconclusive and lacked satisfactory clinical evaluation (Barros D'Sa, 1975a). There is, of course, the possibility that attempts with the technique may have failed but remain unreported.

The exact mechanism of the behaviour and action of the reversed segment which results in transit delay is in some doubt. Information obtained from experimental studies implicates certain gastrointestinal hormones which may mediate in the braking action of segmental reversal (Barros D'Sa et al., 1976b).

The ultimate ideal treatment would of course be intestinal transplantation and replacement of intestine from a human donor. In reality, research in this field is in its early experimental stages and is attended by immunological and other problems such as those of organ donation, perfusion and preservation, as well as apparently insoluble difficulties arising from denervation and interruption of lymphatics. The authors believe that until such time as transplantation of intestine becomes a practical proposition, the reversed distal segment of appropriate size gives the patient the best chance of being restored to reasonable health.

\section{Acknowledgment}

Thanks are due to Miss May Weller for her invaluable help in preparing the manuscript.

\section{References}

Alexandre, J.H. (1970) Extensive resections of the small bowel. A synthesis of the colloquium held in Paris-Lille 1969. Annales de chirurgie, 24, 592.

Althausen, T.L., Doig, R.K., Uyeyama, K. \& Weiden, S. (1950) Digestion and absorption after massive resection of the small intestine. II. Recovery of the absorptive function as shown by intestinal absorption tests in two patients and a consideration of compensatory mechanisms. Gastroenterology, 16, 126.

Barros D'SA, A.A.B. (1975a) Reversed loops in the short gut syndrome. British Medical Journal, 3, 543.

Barros D'SA, A.A.B. (1975b) Pathophysiological aspects of massive small bowel resection with an assessment of theO functional value of reversed segments. M.D.(Hons) thesis, The Queen's University of Belfast.

Barros D'SA, A.A.B. \& BuchanAN, K.D. (1977) The role of? gastrointestinal hormones in the response to massive small bowel resection. Gut, $18,877$.

Barros D'Sa, A.A.B., Kennedy, T.L., Buchanan, K.D. \& PARKs, T.G. (1975a) Gastrointestinal hormonal responses following massive small bowel resection. British Journal of Surgery, 62, 152.

Barros D'Sa, A.A.B., Kennedy, T.L., Parks, T.G. \& BuchanAN, K.D. (1975b) Reversed segments after massive intestinal resection. Is transit delay hormone-mediated? British Journal of Surgery, 62, 656.

Barros D'SA, A.A.B., Kennedy, T.L., Love, A.H.G. \& PARKS, T.G. (1974) An evaluation of reversed segments after massive small bowel resection. British Journal of Surgery, 61, 917.

Barros D'SA, A.A.B., Kennedy, T.L. \& Parks, T.G. (1976a) Immediate and delayed segmental reversal after massive small bowel resection. British Journal of Surgery, 63, 666.

Barros D'SA, A.A.B., Parks, T.G., Kennedy, T.L. \& BuchanaN, K.D. (1976b) Hormonal alterations caused by segmental reversal after massive small bowel resection. European Surgical Research, 8 (Suppl.), 3.

Buxton, B. (1974) Progress report. Small bowel resection and gastric hypersecretion. Gut, 15, 229.

CHEN, KaI-Mo (1969) Massive resection of the small intestine. Surgery, 65, 931.

Colcock, B.P. \& BRAasCH, J.W. (1968) Small intestinal insufficiency. In: Surgery of the Small Intestine in the Adult, chapter 6, pp. 116-129, Vol. VII in series: Major Problems in Clinical Surgery. W. B. Saunders Co., Philadelphia and London.

Dowling, R.H. (1974) The influence of luminal nutrition on intestinal adaptation after small bowel resection and bypass. In: Intestinal Adaptation (Ed. by Dowling, R.H. \& Riecken, E.O.), pp. 35-46. Schattauer Verlag, Stuttgart. 
Dubost, C. (1972) Total enterectomy after avulsion of the jejuno-ileum through a recto-sigmoid wound. Consideration on possibilities of survival without intestine. Chirurgie, 98, 455.

Ellis, H. \& Coll, I. (1968) Antiperistaltic segment for profuse ileostomy diarrhoea. British Medical Journal, 1, 556.

Fletcher, R.F., Henly, A.A., Sammons, H.G. \& Souire, J.R. (1960) A case of magnesium deficiency following massive intestinal resection. Lancet, i, 522.

Frederick, P.L., Sizer, J.S. \& OSBORNe, M.P. (1965) Relation of massive bowel resection to gastric secretion. New England Journal of Medicine, 272, 509.

Gibson, D.L., Carter, R. \& Hinshaw, D.B. (1962) Segmental reversal of small intestine after massive small bowel resection. Successful case with follow-up examination. Journal of the American Medical Association, 182, 952.

Grenier, J.F., Eloy, M.R., Dauchel, J., JAECK, D. \& SAVA, G. (1973) The functional possibilities of the small bowel. Acta gastroenterologica belgica, 36, 36.

Grundberg, A.B., Lopez, A.S. \& Dragstedt, L.R. (1967) Effect of intestinal reversal and massive resection on gastric secretion. Archives of Surgery, 94, 326.

HAYMOND, H.E. (1935) Massive resection of small intestine. Analysis of 257 collected cases. Surgery, Gynecology and Obstetrics, 61, 693.

Herrington JR, J.L., Edwards, W.H., Carter, J.H. \& SAWYERS, J.L. (1968) Treatment of severe post-vagotomy diarrhoea by reversed jejunal segment. Annals of Surgery, 168,522

Kerpel-Fronius, E., Miltenyi, M. \& Gorgenyi, A. (1970) Osmotic diarrhoea due to high sodium chloride intake following subtotal resection of the small intestine. Digestion, $3,20$.

Kieninger, G. (1974) Personal communication.

Kinney, J.M., GoldWyn, R.M., BarR JR, J.S. \& Moore, F.D. (1962) Loss of entire jejunum and ileum and ascending colon: management of a patient. Journal of the American Medical Association, 179, 529.

Koeberle, E. (1881) Resection de deux mètres d'intestin grêle suivie de guérison. Gazette hébdomadaire des sciences médicales de Bordeaux, 18, 55.

Kogan, E., Schapira, A., Janowitz, H.D. \& Adlersberg, D. (1957) Malabsorption following extensive small intestinal resection including inadvertent gastro-ileostomy. Journal of the Mount Sinai Hospital, 24, 399.

Kremen, A.J., Linner, J.H. \& Nelson, C.H. (1954) An experimental evaluation of the nutritional importance of proximal and distal small intestine. Annals of Surgery, 140, 439.

Kunz, H. \& Molitor, H. (1928) Ueber die Ursachens der Ernaehrungsstoerungen nach ausgedehnten Duenndarmresektionen und ihre Behandlung. Archiv für experimentelle Pathologie und Pharmakologie, 132, 50. (Abstracted in Zentralblatt für Chirurgie, 44, 463.)

LACK, L. \& WEINER, I.M. (1967) Role of the intestine during the enterohepatic circulation of bile salts. Gastroenterology, 52, 282.

Leading ARTicle (1975) Reversed loops in the short gut syndrome. British Medical Journal, 2, 709.

LORAN, M.R. \& CARBone, J.V. (1968) The humoral effect of intestinal resection on cellular proliferation and maturation in para-biotic rats. In: Gastrointestinal Radiation Injury (Ed. by M. S. Sullivan), pp. 127-139. Excerpta Medica, Amsterdam.

Mackby, M.J., Richards, V., Gillfillan, R.S. \& Florida, R. (1965) Methods of increasing the efficiency of residual small bowel segments. A preliminary study. American Journal of Surgery, 109, 32.

Meyer, H.W. (1968) Extensive resection of small and large intestine: a further twenty-two year follow-up report. Annals of Surgery, 168, 287.

OSBorne, M.P., Frederick, P.S. \& Blair, D. (1966) Mechanism of gastric hypersecretion following massive intestinal resection. Clinical and experimental observations. Annals of Surgery, 164, 622.

Pотн, E.J. (1969) Use of gastrointestinal reversal in surgical procedures. American Journal of Surgery, 118, 893.

REED, D.L. \& CooN, W.W. (1963) Thromboembolism in patients receiving progestational drugs. New England Journal of Medicine, 269, 622.

RYGICK, A.N. \& NASAROV, L.U. (1969) Antiperistaltic displacement of an ileal loop without twisting its mesentery. Diseases of the Colon and Rectum, 12, 409.

Sautier, C., Pequignot, E., Randriamanana, C. \& Tremolieres, J. (1970) Study of the digestion in 40 patients with resected small intestine. Biologie et gastroenterologie. $1,51$.

Schiller, W.R., Di Rio, L.J.A. \& ANDerson, M.C. (1967) Production of artificial sphincters. Ablation of the longitudinal layer of the intestine. Archives of Surgery, 95, 436.

Sedgwick, C.E. \& Goodman, A.A. (1971) Short bowel syndrome. Surgical Clinics of North America, 51, 675.

VAYre, P., Hureau, J. \& Soyer, R. (1967) Use of antiperistaltic colonic segment interposition to lower small bowel motility following extensive resection (a preliminary examination). Annales de chirurgie, 21, 521.

Venables, C.W., Ellis, H. \& SMith, A.D.M. (1966) Antiperistaltic segments after massive intestinal resections. Lancet, ii, 1390.

Waddell, W.R., Kern, I.F., Halgrimson, C.G. \& WoodBURY, J.J. (1970) A simple jejuno-colic 'valve' for relief of rapid transit and the short bowel syndrome. Archives of Surgery, 100, 438.

Weinstein, L.D., Shoemaker, C.P., Hersh, T. \& Wright, H.K. (1969) Enhanced intestinal absorption after small bowel resection in man. Archives of Surgery, 99, 560.

Weser, E. \& Hernandez, Mary H. (1971) Studies of small bowel adaptation after intestinal resection in the rat Gastroenterology, 60, 69.

WestergaARD, H. \& Dietschy, J.M. (1974) Normal mechanisms of fat absorption and derangements induced by various gastro-intestinal diseases. Medical Clinics of North America, 58, 1413.

Wilkinson, A.W. (1973) Extensive resection of the small intestine. In: Body Fluids in Surgery, 3th edn, chapter 6, pp. 112-120. Churchill Livingstone, London.

Wright, H.K. \& TILSON, M.D. (1973) Malfunction of the small intestine after surgery. In: Postoperative Disorders of the Gastrointestinal Tract, chapter 2. Grune \& Stratton. New York.

Zurier, R.B., Campbell, R.G., Hashim, S.A. \& van Itallie, T.B. (1966) Use of medium-chain triglycerides in management of patients with massive resection of the small intestine. New England Journal of Medicine, 274, 490. 